\title{
Parametric optimization of wire cut electrical discharge machining
}

\author{
M. Durairaj ${ }^{1 *}$, A.K.S. Ansari ${ }^{2}$, M. H. Gauthamkumar ${ }^{2}$ \\ ${ }^{1}$ Department of Mechanical Engineering, Tagore Engineering College, Chennai - 127 \\ ${ }^{2}$ Department of Mechanical Engineering, Bharath University, Chennai - 73 \\ *Corresponding author E-mail: durairaj_tagore@yahoo.com
}

Copyright $\odot 2014$ M. Durairaj et al. This is an open access article distributed under the Creative Commons Attribution License, which permits unrestricted use, distribution, and reproduction in any medium, provided the original work is properly cited.

\begin{abstract}
Wire Electrical Discharge Machining is a manufacturing process whereby a desired shape is obtained using electrical discharges (or) by repetitive spark cycle. Precision and intricate machining are the strengths. Machining parameters tables provided by the machine tool manufacturers often do not meet the operator requirements. Selection of optimum machining and machining parameters combinations is needed for obtaining higher cutting efficiency and accuracy. In this present study, machining is done using Wire-Cut EDM and optimization of surface roughness is done using Taguchi's design of experiments. Experimentation was planned as per Taguchi's L'16 orthogonal array. Each experiment has been performed under different cutting conditions of gap voltage, pulse ON time, and pulse OFF time and Wire feed. Dielectric fluid pressure, wire speed, wire tension, resistance and cutting length are taken as fixed parameters. Inconel 800 was selected as a work material to conduct the experiments. From experimental results, the surface roughness was determined for each machining performance criteria. Signal to noise ratio was applied to measure the performance characteristics deviating from the actual value. Finally, experimental confirmation was carried out to identify the effectiveness of this proposed method.
\end{abstract}

Keywords: Optimization; Taguchi's L-16 Orthogonal Array; Surface Roughness; S/N Ratio.

\section{Introduction}

Electric discharge wire cutting is most commonly called as Wire EDM. It is a process of producing complicated two or three dimensional shapes.In electrical energy based process, electrical energy is directly used to cut the material to get the final shape and size. In electrical discharge machining, metal is removed by producing powerful electric spark discharge between the tool and work material. It can only be used for electrically conducting materials.

This non-traditional techniques has greatly helped in achieving an economic machining of the extremely low machinability materials and difficult to machine materials. The process of material removal is controlled by erosion through a series of electric sparks.

\subsection{Wire cut electrical discharge machining}

Electric discharge wire cutting are most commonly called Wire EDM. It is a process of producing complex two or three dimensional shapes using simple wire eroding the metal from an electrically conducting metal. Although WEDM machining is complex, the use of this machining process in industry has increased because of its capability in cutting complicated forms, especially created in hard materials.

\subsubsection{Process mechanism of wire cut EDM}

1) The following fig1 shows the schematic layout of the Wire cut Electrical discharge machining process. 
2) A very thin wire of diameter $0.25 \mathrm{~mm}$ of circular cross section is used as electrode (tool).

3) The wire is stretched and moved between two rollers.

4) The function of servomechanism is to maintain a very small gap, known as "spark gap" ranges of 0.005 to $0.05 \mathrm{~mm}$ between the work piece and the tool.

5) Work piece is mounted on the table which is operated by the control unit.

6) A very thin wire made of brass is passed and this wire is operated by the feed mechanism.

7) Dielectric fluid (De-mineralised water) is passed over the work piece and the wire (tool) by using a pump. When D.C supply is given to the circuit, spark is produced in the gap between the wire and the work piece.

8) When the voltage across the gap becomes sufficiently large (more than 250V), the high power spark is produced. So, the dielectric breaks down occurs and electrons are emitted from the cathode (tool) and the gap is ionized.

9) The spark occurs in an interval of 10 to 30 microseconds and with a current density of 15-500A per mm approximately. So thousands of spark discharge occurs per second across the gap between the tool and the work, which results in temperature rise to about $10000^{\circ} \mathrm{C}$.

10) At this high temperature, work piece metal is melted, eroded and some of it get vaporized. In this way the metal is removed from the work piece.

11) The removed fine material particles are carried away by dielectric fluid circulated around it.

12) When the voltage drops to about 12 Volts, the spark discharge extinguishes and the dielectric fluid once again becomes deionised.

\section{Problem definition}

Wire EDM involves complex physical process including heating and cooling. The electrical discharge energy depends on various operating parameters which in turn will influence the machining efficiency and the surface quality. Hence, the operating parameters gap voltage, feed, pulse on time, pulse off time, gap voltage, peak current intensity, polarity, wire tension, capacitance and wire speed etc. should be chosen properly so that a better performance can be obtained. Surface Roughness $(\mathrm{Ra})$, are most important responses in WEDM. The selection of appropriate machining parameters for WEDM is difficult and depends on the operator's experience and machining parameter tables provided by the machine-tool builders. Achieving this difficult task will result in increasing the efficiency of the WEDM. [1]

\subsection{Objective}

The main objective of the present study is to analyze the effect of process parameters on the surface roughness in WireCut Electrical Discharge Machining (WEDM).

The specific objective is to:

- Employ Taguchi's technique to find out the optimum combination of machining parameters and their levels in the WEDM process to optimize the surface roughness.

\subsection{Parameters considered in this experiment}

\subsubsection{Input parameters}

- Gap voltage

- Wire feed

- $\quad$ Pulse on time

- $\quad$ Pulse off time

\subsubsection{Output parameters}

- $\quad$ Surface roughness

\subsubsection{Surface roughness}

The surface roughness is defined as the measure of the texture of the surface.

\section{Materials and methods}

\subsection{Work material}


Inconel 800 is used for the present investigation. [5]

The table 1 shows the chemical composition of Inconel 800.

Table 1: Chemical Composition of the Work Material

\begin{tabular}{ccccccccccc}
\hline Chemical Composition Wt\% & $\mathrm{Ni}$ & $\mathrm{Cr}$ & $\mathrm{Fe}$ & $\mathrm{Mn}$ & $\mathrm{Ti}$ & $\mathrm{Si}$ & $\mathrm{C}$ & $\mathrm{Al}$ & $\mathrm{Cu}$ & $\mathrm{Ph}$ \\
\hline & 31.67 & 20.42 & 44.88 & 1.24 & 0.21 & 0.53 & 0.068 & 0.02 & 0.296 & 0.027 \\
\hline
\end{tabular}

\subsection{Taguchi's approach to design of experiments}

Taguchi methods provide an efficient and systematic way to optimize designs for performance, quality and cost. [1]Taguchi's approach to parameter design provides the design engineer with a systematic and efficient method for determining near to optimum design parameters for performance and cost. The objective is to select the best combination of control parameters so that the process is most robust. The Taguchi method utilizes orthogonal arrays from design of experiments theory to study a large number of variables with a small number of experiments. [2,4]Using orthogonal arrays significantly reduces the number of experimental configurations to be studied. Furthermore, the conclusions drawn from small-scale experiments are valid over the entire experimental region spanned by the control factors and their settings. According to the determination of transformation function via the mathematical relations between input and output vectors, the capability computation of the fitness function value in optimization process will be determined. [3,5]The Taguchi method can reduce research and development costs by improving the efficiency of generating information needed to design systems that are insensitive to usage conditions, manufacturing variation, and deterioration of parts. Many researchers have attempted to analyse and optimize single and multiple performance of a manufacturing process using Taguchi methodology. [6]

Table 2: Process Parameters and their Levels

\begin{tabular}{llllll}
\multicolumn{7}{c}{ Table 2: Process Parameters and their Levels } \\
\hline Process parameters & Unit & Level 1 & Level 2 & Level 3 & Level 4 \\
\hline Pulse- on Time $\left(\mathrm{T}_{\text {on }}\right)$ & $\mu \mathrm{s}$ & 2 & 4 & 6 & 8 \\
Pulse-off Time $\left(\mathrm{T}_{\text {off }}\right)$ & $\mu \mathrm{s}$ & 4 & 6 & 8 & 10 \\
Wire Feed & $\mathrm{mm} / \mathrm{min}$ & 4 & 6 & 8 & 10 \\
Gap Voltage & Volts & 40 & 50 & 60 & 70 \\
\hline
\end{tabular}

\section{Results \& discussion}

The response of Surface roughness reported in the above table is used to calculate the signal to Noise ratio( $/ \mathrm{N})$. Since Surface roughness is desired to be at minimum, the Lower the Better characteristic is used for $\mathrm{S} / \mathrm{N}$ ratio calculation. The formula for $\mathrm{S} / \mathrm{N}$ ratio is given by the eqn.

$\mathrm{S} / \mathrm{N}=-10 \log \left(1 / \mathrm{r} \Sigma \mathrm{Yi}^{2}\right)$

$\mathrm{i}=1$

Table 3: Machining Parameter and Corresponding Outputs

\begin{tabular}{lllllll}
\hline S.No & $\begin{array}{l}\text { Pulse on } \\
\text { time }(\mu \mathrm{s})\end{array}$ & Pulse off time $(\mu \mathrm{s})$ & $\begin{array}{l}\text { Wire feed } \\
(\mathrm{mm} / \mathrm{min})\end{array}$ & Gap voltage $(\mathrm{V})$ & Surface Roughness $\left(\mathrm{R}_{\mathrm{a}}\right)$ & S/N Ratio for R $_{\mathrm{a}}$ \\
\hline 1 & 2 & 4 & 4 & 40 & 3.01 & -9.542 \\
2 & 2 & 6 & 6 & 50 & 2.09 & -8.881 \\
3 & 2 & 8 & 8 & 60 & 2.65 & -8.465 \\
4 & 2 & 10 & 10 & 70 & 2.31 & -7.272 \\
5 & 4 & 4 & 6 & 60 & 2.55 & -7.993 \\
6 & 4 & 6 & 8 & 70 & 2.49 & -7.924 \\
7 & 4 & 8 & 10 & 40 & 3.27 & -10.021 \\
8 & 4 & 10 & 4 & 50 & 2.86 & -9.127 \\
9 & 6 & 4 & 8 & 70 & 2.58 & -8.232 \\
10 & 6 & 6 & 10 & 60 & 2.90 & -8.028 \\
11 & 6 & 8 & 4 & 50 & 2.43 & -7.712 \\
12 & 6 & 10 & 6 & 40 & 2.64 & -9.432 \\
13 & 8 & 4 & 10 & 50 & 3.09 & -8.771 \\
14 & 8 & 6 & 8 & 40 & 3.00 & -9.743 \\
15 & 8 & 8 & 6 & 70 & 3.07 & -9.799 \\
16 & 8 & 10 & 4 & 60 & 3.15 & \\
\hline
\end{tabular}


Table 5: S/N Ratios for Each Parameter at Four Levels

\begin{tabular}{cccccc}
\hline \multirow{2}{*}{ S. No } & \multirow{2}{*}{ Factor } & Level1 & Level2 & Level3 & Level4 \\
\cline { 3 - 6 } & & -9.219 & -8.873 & -8.571 & -8.293 \\
2 & Gap voltage & -9.045 & -8.762 & -8.376 & -8.773 \\
3 & Wire feed & -8.54 & -8.766 & -8.101 & -9.549 \\
4 & Pulse on time & -8.885 & -8.429 & -8.986 & -8.65 \\
\hline
\end{tabular}

Main effects plot for $\mathrm{S} / \mathrm{N}$ ratio Data means
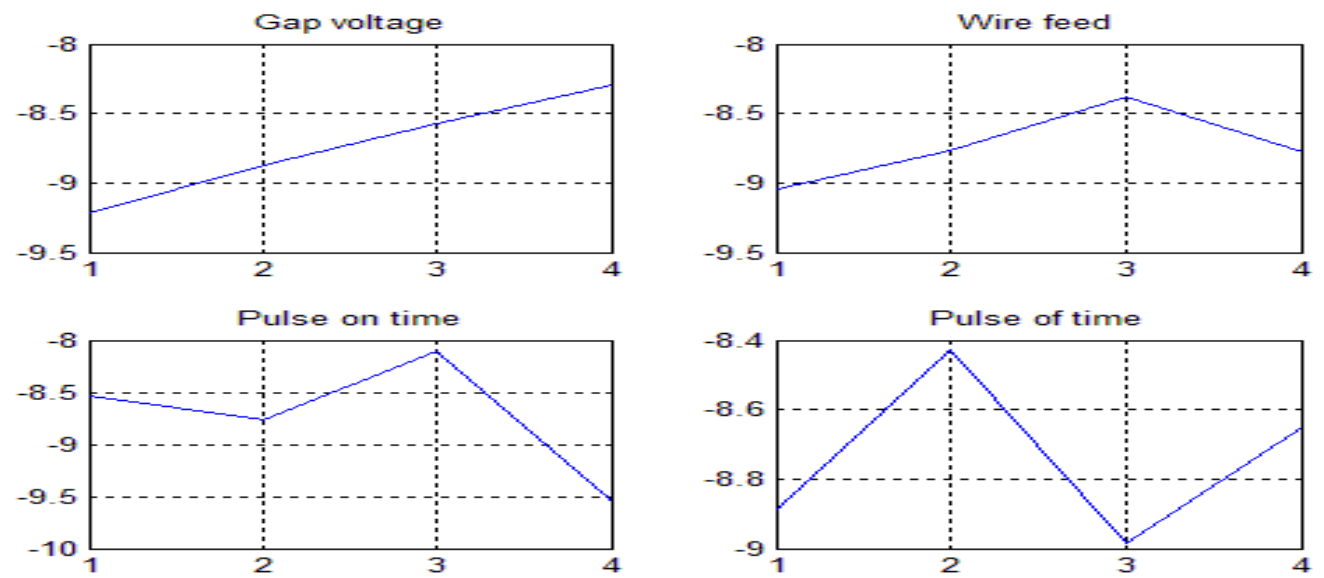

Fig. 1: Signal to Noise Ratio: Smaller Is Better

Table 6: Optimum Conditions

\begin{tabular}{llll}
\hline S.No & Factor & Level & Optimum Value \\
\hline 1 & Gap voltage & 1 & 40 \\
2 & Wire feed & 1 & 4 \\
3 & Pulse on time & 4 & 8 \\
4 & Pulse off time & 3 & 8 \\
\hline
\end{tabular}

\section{Conclusion}

Experimental investigation on wire electrical discharge machining of Inconel-800 has been carried out and optimized using Taguchi's Signal to noise ratio technique and the optimum parametric combination obtained for Surface roughness is $40 \mathrm{~V}$ of Gap voltage, $4 \mathrm{~mm} / \mathrm{min}$ of Wire Feed, and $8 \mu$ s of Pulse on Time and $8 \mu$ s of Pulse off Time.

\section{References}

[1] S. S. Mahapatra \& Amar Patnaik (2006) 'Optimization of wire electrical discharge machining (WEDM) process parameters using Taguchi method' Int J Adv Manuf Technol.

[2] Muthu Kumar V, Suresh Babu A, Venkatasamy R and Raajenthiren M (2010) 'Optimization of the WEDM Parameters on Machining Incoloy800 Super alloy with Multiple Quality Characteristics' Int J of Engg science and tech.

[3] S. S. Mahapatra, Amar Patnaik 'Parametric optimization of wire electrical discharge machining (WEDM) process using taguchi method'

[4] Vishal Parashar, A. Rehman, J.L. Bhagoria and Y.M. Puri(2009) 'Investigation and Optimization of Surface Roughness for Wire Cut Electro Discharge Machining of SS304L using Taguchi Dynamic Experiments' Int J Engg studies Volume 1, Number 4, pp. $257-267$.

[5] Muthu Kumar V, Suresh Babu A, Venkatasamy R and Raajenthiren M (2010) 'Optimization of the WEDM Parameters on Machining Incoloy800 Super alloy with Multiple Quality Characteristics' Int J of Engg science and tech.

[6] K. Kanlayasiri, S. Boonmung,(2007) 'An investigation on effects of wire-EDM machining parameters on surface roughness of newly developed DC53 die steel' Journal of Materials Processing Technology.187: 26-29. 